\title{
Panel says less-is-more when it comes to nutrition ratings on packaged foods
}

Published at www.cmaj.ca on Oct. 25

$\mathrm{T}$ he nutrition rating symbols that are splashed across the front of packaged foods are so confusing that a less-is-more approach is needed to cut through the clutter and help consumers figure out which foods are the healthiest, a prestigious United States medical panel has concluded.

A report from the Institute of Medicine recommends that voluntary rating systems, developed by food manufacturers, retailers, nutrition groups, governments and others, stick to highlighting the four food components that are most closely associated with the biggest health concerns: calories, saturated fat, trans fat and sodium.

These nutrients, the report says, are "routinely overconsumed" and most strongly linked with health problems such as obesity, heart disease, high blood pressure, type 2 diabetes and certain types of cancer.

To quiet the nutritional cacophony that blares at consumers when they walk through a grocery store, the report recommends stripping out of the ratings systems information on a number of other nutrients, including total fat, cholesterol, total carbohydrate, total or added sugars, protein, fibre, vitamins, and minerals other than sodium.

The institute studied 20 different food labelling schemes, devised by groups in the US and elsewhere, featuring various check marks, tokens, spots and other symbols.

These unregulated systems are known as "front of package," or FOP, nutrition ratings, and are separate from the standardized panel of nutrition facts that the US government requires on most packaged foods. As front-of-package labelling has multiplied, the report says, "it has become easy for consumers to be confused about critical nutrition information. Adding to the confusion, manufacturers use a variety of FOP

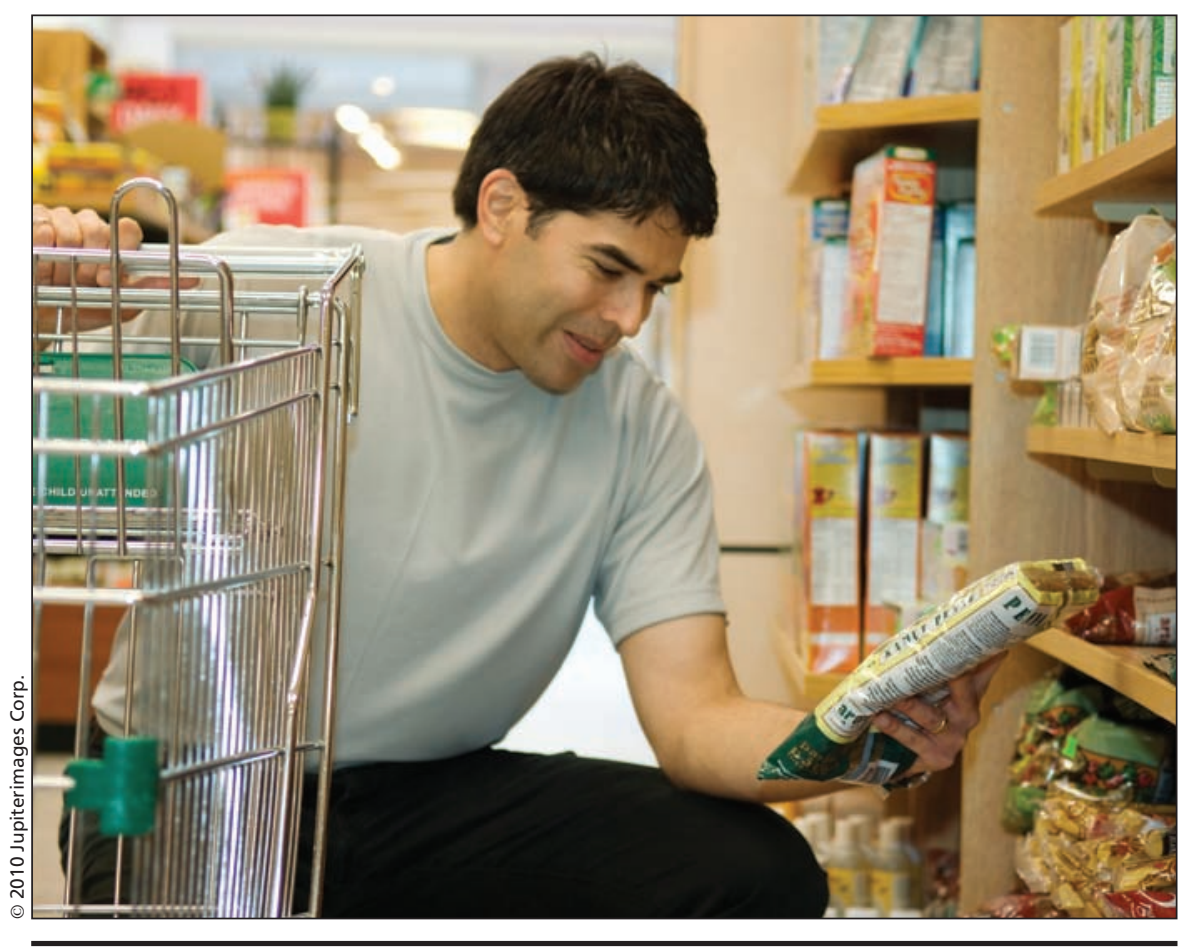

The United States Institute of Medicine says front-of-package food labelling should be trimmed down to a core four components to make things less confusing for consumers.

nutrition rating systems, with different and often conflicting criteria that can yield varying results."

For example, when the ratings for six cereals were compared, all six met the desired criteria for Heart Check (developed by the American Heart Association) and for Smart Choices (designed by an industry/nonindustry consortium); four met the criteria for Healthy Ideas (Giant Foods), Smart Spot (PepsiCo.) and Health Check (Heart and Stroke Foundation of Canada); three met the criteria for Sensible Solutions (Kraft); and two met the criteria for Choices (nonindustry experts).

Tufts University Professor Alice Lichtenstein, vice chair of the institute committee that prepared the report, says the panel felt a "single, consistent system" for ratings would help consumers zero in on the most important information. Still to come, she added, is a second phase of the committee's study, which will look at how consumers use the nutrition information that's provided by the ratings systems.

The private Center for Science in the Public Interest (CSPI), which had pushed for the report, said in a statement that it believed added sugars should also be included in the food rating systems, at least for some foods, such as soda. And CSPI said that rather than highlight the presence of trans fat, the government should ban outright the artificial variety of trans fat, which comes from partially hydrogenated oil.

Bill Jeffery, CSPI's national coordinator for Canada, says the current ratings systems in some cases are so lax that even "nutritional train wrecks like Kool-Aid and Kraft Dinner" qualify for Kraft's "Sensible Solutions" designation. 
"The front of the package can be an incredibly useful tool to help shoppers efficiently choose healthier products and avoid junk food dressed up like health food," Jeffery says. "But food companies strongly resist government efforts to ensure consumers get a balanced view."

Marion Nestle, a professor of nutrition at New York University in New York City, New York, says the institute's recommended course of action would "get rid of the cacophony of rating schemes now out there. What it will not do is get rid of nutrient-content claims and anything else positive that companies can get away with" to persuade consumers to buy their products.

The Grocery Manufacturers Association, which represents the food and beverage industries, said in a statement that the report would be helpful "in increasing focus on the types of front- of-pack nutrition labelling systems that are most helpful to consumers."

The Institute of Medicine was created by Congress to advise the government on health matters. The institute's report was sponsored by the US Centers for Disease Control and Prevention and the US Food and Drug Administration. — Nancy Benac, Washington, DC

DOI:10.1503/cmaj.109-3707 